\title{
Pre- and Post-Infection Activity of Azoxystrobin, Pyraclostrobin, Mefenoxam, and Phosphite Against Leather Rot of Strawberry, Caused by Phytophthora cactorum
}

\author{
A. Rebollar-Alviter, L. V. Madden, and M. A. Ellis, Department of Plant Pathology, The Ohio State Univer- \\ sity/OARDC, Wooster 44691
}

\begin{abstract}
Rebollar-Alviter, A., Madden, L. V., and Ellis, M. A. 2007. Pre- and post-infection activity of azoxystrobin, pyraclostrobin, mefenoxam, and phosphite against leather rot of strawberry, caused by Phytophthora cactorum. Plant Dis. 91:559-564.

Pre- and post-infection activity of azoxystrobin, pyraclostrobin, mefenoxam, and phosphite against leather rot of strawberry, caused by Phytophthora cactorum, was determined under greenhouse conditions. Strawberry plants (cv. Honeoye) were grown in pots, and attached fruit at the green-to-white stage of development were used in evaluations. Plants and fruit were sprayed to runoff with the above-mentioned fungicides either before (protectant) or after (curative) inoculation with a zoospore suspension $\left(10^{5}\right.$ zoospores $\left./ \mathrm{ml}\right)$ of $P$. cactorum. Inoculated plants with fruit were placed in a mist chamber for $12 \mathrm{~h}$ to ensure infection. Fungicides were applied at either 2,4 , or 7 days before inoculation or $13,24,36$, or $48 \mathrm{~h}$ after inoculation. Incidence (proportion of diseased fruit) was recorded 6 days after inoculation. Azoxystrobin and pyraclostrobin provided protectant activity for up to 7 days before inoculation, but only slight curative activity when applied $13 \mathrm{~h}$ after inoculation. Phosphite and mefenoxam also provided protection for up to 7 days, as well as curative activity of at least $36 \mathrm{~h}$. There were no significant differences in protectant activity among the QoI fungicides azoxystrobin and pyraclostrobin, phosphite and mefenoxam.
\end{abstract}

Additional keywords: phosphorous acid, strobilurin

Leather rot of strawberry is caused by the oomycete Phytophthora cactorum (Lebert \& Cohn) J. Schröt (8). The disease was first reported in the southern United States in 1924 (31). Since then, leather rot has been reported in several states and is an important disease in Europe and parts of Asia (19). Leather rot is associated with wet weather (flooding or saturated soils) and usually occurs sporadically, depending upon local weather conditions. When the disease develops, losses can be severe. Fruit losses of 20 to $30 \%$ were common in many commercial fields during a 1981 epidemic in Ohio, and some growers experienced a $50 \%$ crop loss (6). $P$. cactorum can infect fruit at any stage of development $(12,19)$. Infected green fruit become dark brown and appear leathery. On mature berries, infections may result in little color change or discoloration ranging from whitish-gray to purple in color. In addition to direct losses from fruit rot, berries that are affected by leather rot have a distinctive and very unpleasant odor and taste. Even healthy tissue on a slightly rotted berry is

Corresponding author: M. A Ellis

E-mail: ellis.7@osu.edu

Accepted for publication 19 November 2006.

doi:10.1094/PDIS-91-5-0559

(C) 2007 The American Phytopathological Society bitter. This presents a special problem to growers in pick-your-own operations. An infected mature berry with little color change may appear normal and be harvested and processed with healthy berries. Growers have experienced complaints from customers about off-flavored jams and jellies after processing fruit from fields where leather rot was a problem (M. A. Ellis, unpublished data). Therefore, the tolerable incidence of leather rot is near zero, and some Midwestern growers have reported closing plantings to pick-yourown customers as soon as leather rot was detected.

The disease is controlled using cultural practices such as site selection, improving soil drainage, and the use of straw mulch $(7,19)$. To date, no cultivar resistance to leather rot has been reported. Fungicides are an important component of the disease management program (19). Currently, mefenoxam, fosetyl-Al, and several phosphite fungicides are registered for control of leather rot in the United States. All of these fungicides provide effective control of leather rot (28). In addition, the QoI (strobilurin) fungicides azoxystrobin and pyraclostrobin provide excellent activity against leather rot under very high disease pressure in the field (28). The efficacy of these QoI fungicides in field trials was similar to mefenoxam and phosphite fungicides (28). QoI fungicides represent an important addition to the fungicides cur- rently used for control of strawberry diseases in Ohio. Azoxystrobin and pyraclostrobin are registered for control of anthracnose fruit rot of strawberry in addition to several leaf diseases; however, leather rot currently is not on the label. Both fungicides are frequently used on strawberry in Ohio (M. Ellis, unpublished data), and it would be beneficial to strawberry growers if leather rot was included on the label.

The physical mode of action of a fungicide may involve protectant, curative, postsymptom, and vapor activity (39). Understanding the physical mode of action of a fungicide should contribute to its more efficient use through optimizing application timing based on the host-pathogenfungicide interaction (39).

Several studies have been conducted on the physical mode of action of azoxystrobin. Wong and Wilcox (39), working with grapevine downy mildew (Plasmopara viticola), reported that azoxystrobin provided $100 \%$ control when applied 1 to 5 days before inoculation, but postinfection applications did not provide a satisfactory reduction of downy mildew incidence; however, a significant reduction of sporulation and resporulation was observed. Similar results on the protectant and post-infection activity of azoxystrobin have been reported in other pathosystems $(1,3,34)$. Studies with other QoI fungicides such as pyraclostrobin and trifloxystrobin against Cercospora beticola also reported excellent protectant activity but limited post-infection activity (17).

Preventive and curative applications of mefenoxam have been very effective against Pythium aphanidermatum, the causal agent of Pythium blight of turfgrass (34). Applications of metalaxyl (same mode of action as mefenoxam) provided excellent control of grape downy mildew when applied as a protectant, and provided curative activity for up $24 \mathrm{~h}$. Metalaxyl also provided a significant reduction in sporulation when applied after symptom development (39). Post-infection applications of phosphorous acid (phosphite) significantly reduced the incidence and severity of grape downy mildew when applied up to 10 days after inoculation (38).

Although the efficacy of azoxystrobin, pyraclostrobin, mefenoxam, and phosphite fungicides for control of leather rot has been demonstrated in previous studies 
$(7,28)$, their physical mode of action against Phytophthora cactorum is unknown. At present, all of these fungicides are applied in prophylactic (protectant) programs regardless of whether actual infection periods have occurred (19). If any of these materials have curative activity, they could be applied after infection periods are identified and, therefore, applied only when needed. This approach to disease management conforms to current integrated pest management (IPM) strategies and could result in improved fungicide timing, improved disease control, less overall use of fungicides (especially in drier growing seasons), and increased profits for growers. A disease predictive model for strawberry leather rot has been developed $(12,13,29)$; however, the lack of fungicides with curative activity has prevented its further development and implementation. If any of the previously mentioned fungicides have curative activity, they may have potential for use within a disease forecasting systems for leather rot management.

The objective of this research was to determine the pre-infection (protectant) and post-infection (curative) activity of mefenoxam, phosphite, azoxystrobin, and pyraclostrobin against $P$. cactorum, the causal agent of strawberry leather rot.

\section{MATERIALS AND METHODS}

Isolation, culture maintenance, and inoculum production. Isolates of $P$. cactorum were obtained from diseased fruit from a commercial strawberry planting plot near Wooster, OH in summer 2003 using the oomycete-selective media PBNC (containing pentachloronitrobenzene, benomyl, neomycin sulfate, and chloramphenicol; 12). Isolates were transferred to test tubes containing PBNC and stored in a cold room at $4^{\circ} \mathrm{C}$ until needed. Based on pathogenicity experiments, a highly virulent isolate was

To produce zoospores for inoculations, cultures first were grown for 4 days on petri dishes containing lima bean agar medium. After this time, 16 5-mmdiameter plugs were extracted from the edge of actively growing colonies and placed into 9-cm-diameter plastic petri dishes containing $20 \mathrm{ml}$ of diluted lima bean broth (12). Dishes were incubated for 5 to 7 days at $22^{\circ} \mathrm{C}$ in continuous light; this was sufficient incubation time to induce abundant sporangia production. The broth selected for use in these studies.

was poured off and replaced with $20 \mathrm{ml}$ of sterile distilled water. Zoospore production was induced by incubating the cultures at $4^{\circ} \mathrm{C}$ for $40 \mathrm{~min}$ followed by $30 \mathrm{~min}$ at room temperature (12). Prior to inoculation, the zoospore concentration was adjusted to $10^{5}$ zoospores $\mathrm{ml}^{-1}$ using a hemacytometer.

Plant material and inoculations. Strawberry plants (cv. Honeoye) were grown for 3 weeks in the greenhouse in 15-cm-diameter plastic pots containing a 2:2:1 mixture of peat, steam disinfested soil, and sand. Water was provided to each individual pot by a drip irrigation system. Temperature in the greenhouse was maintained at $25 \pm 2^{\circ} \mathrm{C}$ with a 12 -h photoperiod. Attached fruit at the green to white stage of development were used for all inoculations. Ten attached fruit were used for each of four replications of all treatments. Fruit were inoculated with a zoospore suspension of $10^{5}$ zoospores $\mathrm{ml}^{-1}$ using an electric atomizer connected to a hand-held sprayer. $P$. cactorum requires a very short wetness duration (as little as $2 \mathrm{~h}$ ) to cause high levels of fruit infection (13). To promote infection, inoculated plants with fruit were incubated in the dark in a clear plastic mist chamber ( 2.3 by 1.4 by $1 \mathrm{~m}$ ), with an air atomizer mist nozzle (Spraying Systems Co. Wheaton, IL), which provided $12 \mathrm{~h}$ of wetness at $22 \pm 2^{\circ} \mathrm{C}$. After this wetness period, plants were allowed to air dry for $1 \mathrm{~h}$ before being returned to the greenhouse. Plants were watered using a drip irrigation system to prevent further wetting of the fruit. Disease incidence (proportion of diseased fruit) was recorded 6 days after inoculation.

Fungicide application. Commercial formulations of mefenoxam (Ridomil Gold EC; Syngenta Crop Protection, Greensboro, NC) at $0.572 \mathrm{~kg}$ a.i/ha, phosphite (Agri-Fos; Agrichem Manufacturing Industries, Queensland, Australia) at $2.34 \mathrm{~kg}$ a.i/ha, azoxystrobin (Abound 2.08 EC; Syngenta Crop Protection) at $0.257 \mathrm{~kg}$ a.i/ha, and pyraclostrobin (Cabrio 20 EG; BASF Corporation, Research Triangle Park, NC.) at $0.196 \mathrm{~kg}$ a.i $/$ ha were used in all treatments. The concentration of each fungicide used in this experiment was based on the recommended label rate suspended in 473 liters of water/ha.

Timing of fungicide applications. Fungicides were evaluated as pre- and post-infection applications. To evaluate pre-infection activity, plants and fruit were

Table 1. Mean incidence of leather rot of strawberry corresponding to different days before inoculation (DBI) of fungicide application ${ }^{\mathrm{Z}}$

\begin{tabular}{lrrr}
\hline Treatment & 2 DBI & 4 DBI & 7 DBI \\
\hline Pyraclostrobin & $0.0 \mathrm{~b}$ & $0.0 \mathrm{~b}$ & $4.2 \mathrm{~b}$ \\
Azoxystrobin & $0.0 \mathrm{~b}$ & $0.0 \mathrm{~b}$ & $0.0 \mathrm{c}$ \\
Mefenoxam & $0.0 \mathrm{~b}$ & $0.0 \mathrm{~b}$ & $0.0 \mathrm{c}$ \\
Phosphorous acid & $0.0 \mathrm{~b}$ & $0.8 \mathrm{~b}$ & $0.0 \mathrm{c}$ \\
Control & $61.7 \mathrm{a}$ & $75.8 \mathrm{a}$ & $59.2 \mathrm{a}$ \\
\hline
\end{tabular}

${ }^{\mathrm{z}}$ Means followed by the same letter within columns are not significantly different at $P=0.05$ according to the least significant difference calculated with the Generalized Linear Mixed Model (SAS). sprayed to runoff with the fungicide suspension using a hand-held sprayer at 2,4 , and 7 days before inoculation.. Seven days of pre-infection activity was the longest period evaluated because, after 7 days, fruit began to get overripe. Sprayed plants with attached fruit were allowed to dry and then maintained in the greenhouse until the time of inoculation. To test for postinfection activity, attached fruit first were inoculated with a zoospore suspension and then incubated for $12 \mathrm{~h}$ in the mist chamber as previously described. After $12 \mathrm{~h}$, plants were removed from the mist chamber and allowed to air dry for $1 \mathrm{~h}$ before being sprayed with fungicide suspensions at $13,24,36$, and $48 \mathrm{~h}$ after inoculation. The untreated control was sprayed with water only. After each fungicide application, plants were allowed to dry after which they were transferred to the greenhouse. Plants were watered with a drip irrigation system to prevent further wetting of fruit. Six days after inoculation, incidence (proportion of diseased fruit) was recorded.

Experimental design and data analysis. The experiment was conducted in a complete randomized block design with four replications. Treatments consisted of the fungicide and the application timing, either before (protectant applications) or after (curative applications) inoculation. Each timing and fungicide combination was conducted three times (with four replications of each repetition of the experiment). Incidence was recorded as proportion of fruit with disease symptoms. Because of the binary nature of the response and the presence of more than one random effect, the experiment was analyzed by using Generalized Linear Mixed Models $(20,27)$. Fungicides and application timing where considered fixed effects, and replications nested within experiment repetitions was considered as random effects. The GLIMMIX procedure of SAS was used to fit the model to the data and determine the significance of the main effects (timing and fungicide) and interactions. The logit link function and binomial distribution were utilized. Model fit was evaluated by considering the pattern of Pearson residuals against the estimated linear predictor and the ratio of the generalized $\chi^{2}$ by its degrees of freedom (20). Pairwise treatment comparisons were conducted on the proportion of diseased fruit in the logit scale using the LSMEANS option of GLIMMIX procedure (SAS). Disease incidence in the logit scale was back transformed to proportion of diseased fruit by requesting the inverse link function of the linear predictor.

\section{RESULTS}

All fungicides tested provided almost $100 \%$ disease control for applications made up to 7 days prior to inoculation (Table 1). The effect of all treatments was 
significantly different $(P<0.05)$ from the untreated control for all times of testing, and there were no significant differences in disease control among any of the fungicide treatments within each time of testing. With only one exception, no diseased fruit were found in any fungicide treatment
Because the fungicides provided nearly $100 \%$ control up to 7 days, it is probable that the fungicides would provide protection for longer periods.

When applied as post-inoculation (curative) treatments, there were significant differences $(P<0.001)$ in the level of dis-

Table 2. Significance of post-infection fungicide timing, fungicide treatment, and interaction effect on the incidence of leather rot of strawberry based on a Generalized Linear Mixed Model (SAS) fitted to the data

\begin{tabular}{|c|c|c|c|c|}
\hline \multirow[b]{2}{*}{ Effect } & \multicolumn{2}{|c|}{ Degrees of freedom $^{z}$} & \multirow[b]{2}{*}{$F$ value } & \multirow[b]{2}{*}{$P$ value } \\
\hline & $\mathbf{d f _ { N }}$ & $\mathbf{d f}_{\mathrm{D}}$ & & \\
\hline Time & 3 & 208 & 32.89 & 0.0001 \\
\hline Treatment & 4 & 208 & 5.65 & 0.0002 \\
\hline Time $\times$ treatment & 12 & 208 & 4.96 & 0.0001 \\
\hline
\end{tabular}

${ }^{\mathrm{z}}$ Numerator $\left(\mathrm{df}_{\mathrm{N}}\right)$ and denominator $\left(\mathrm{df}_{\mathrm{D}}\right)$ degrees of freedom, estimated with the Satterthwaite option of SAS.

ease control among fungicide treatments at different times of testing as indicated by the significant interaction between effects (Table 2). The two QoI fungicides (azoxystrobin and pyraclostrobin) had similar post-infection activity. Although both fungicides showed some post-infection activity at $13 \mathrm{~h}$ after inoculation, they had no post-infection activity when applied at 24 , 36 , and $48 \mathrm{~h}$ after inoculation (Figs. 1 and 2). At $13 \mathrm{~h}$ after inoculation, there were significantly fewer diseased fruit in treatments with QoI fungicides than the untreated control, with no significant differences between fungicides (Figs. 1 and 2). Although both QoI fungicides significantly reduced the incidence of leather rot at 13 $\mathrm{h}$, disease incidence in both treatments was at least $40 \%$ compared with $70 \%$ in the
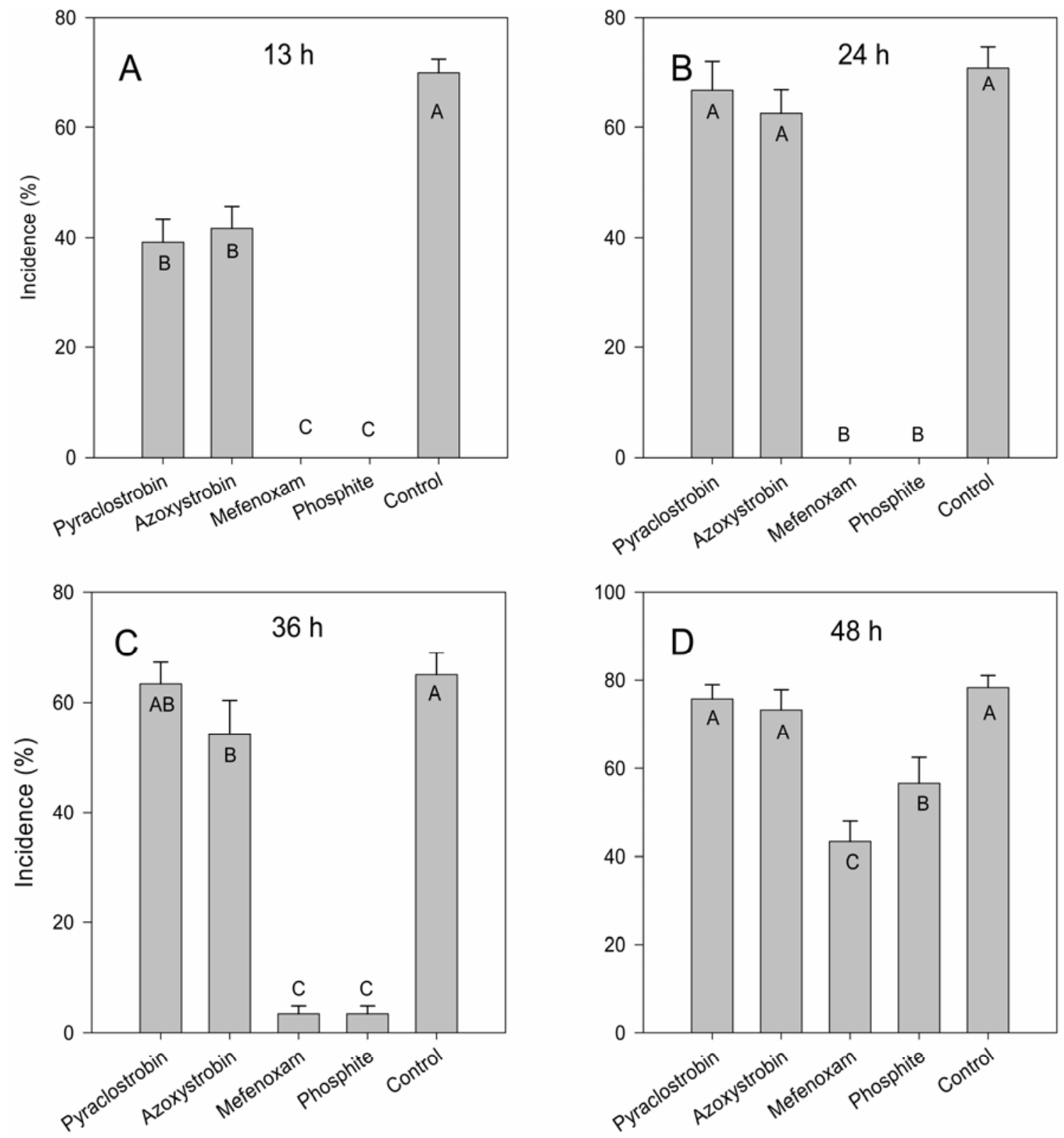

Fig. 1. Effect of post-infection applications of pyraclostrobin, azoxystrobin, mefenoxam, and phosphite against Phytophthora cactorum. Fungicides were applied A, 13; B, 24; C, 36; or $\mathbf{D}, 48$ h after inoculation with P. cactorum zoospores. Disease incidence is expressed as percentage of diseased fruit. Bars represent mean disease incidence of four replications. Treatments with the same letter are not significantly different according to the least significant difference calculated after fitting a Generalized Linear Mixed Model $(P=0.05)$ to the data. 
untreated control. This level of disease control would not be commercially acceptable. Whereas the QoI fungicides tested here have excellent protectant activity against leather rot, our results suggest that their curative activity is very weak.

Mefenoxam and phosphite were very effective for controlling leather rot in both pre-infection and post-infection applications. Both fungicides provided excellent protectant activity for up to 7 days (Table 1 ), and excellent post-infection activity for up to $36 \mathrm{~h}$ after inoculation (Figs. 1 and 2). Mefenoxam and phosphite provided a significant reduction in disease incidence when applied $48 \mathrm{~h}$ after infection; however, disease incidence in treated plants was 42 and $55 \%$, respectively, compared with $80 \%$ in the untreated control (Fig. 1). This level of disease control is commercially unacceptable. No effects on disease development were observed with any of the fungicides tested in this study when applied at $60 \mathrm{~h}$ after inoculation in preliminary experiments (data not shown).

\section{DISCUSSION}

All of the fungicides used in this study previously have been reported to have good protectant activity against various pathogens $(1,2,9,10,28,38)$. In addition, all of these fungicides have been reported to provide excellent control of leather rot in the field under conditions highly conducive to disease development $(7,28)$. The results of this study indicate that the control of leather rot provided by azoxystrobin and pyraclostrobin in previous field trials was due to protectant activity. Control of leather rot provided by mefenoxam and phosphite could have been due to either protectant or curative activity.

Overall, our results with azoxystrobin and pyraclostrobin are similar to those reported in other pathosystems where postinfection activity in general does not extend beyond $48 \mathrm{~h}(3,17,39)$. However, post-infection activity of QoI fungicides varies according to the host-pathogen combination. For example in experiments conducted with downy mildew of grape, azoxystrobin was not effective in controlling the disease when applied at $24 \mathrm{~h}$ after inoculation (39), but provided good control (77\%) of Pythium blight of turfgrass caused by Pythium aphanidermatum when applied at low levels of disease severity between 24 and $48 \mathrm{~h}$ after inoculation (34). Likewise, when azoxystrobin was applied in post-infection sprays against grape black rot, it provided some disease control, although the post-infection activity was dependent on the amount of inoculum used (14). Similarly, good post-infection activity of azoxystrobin has been observed against citrus scab for up to $72 \mathrm{~h}$ after
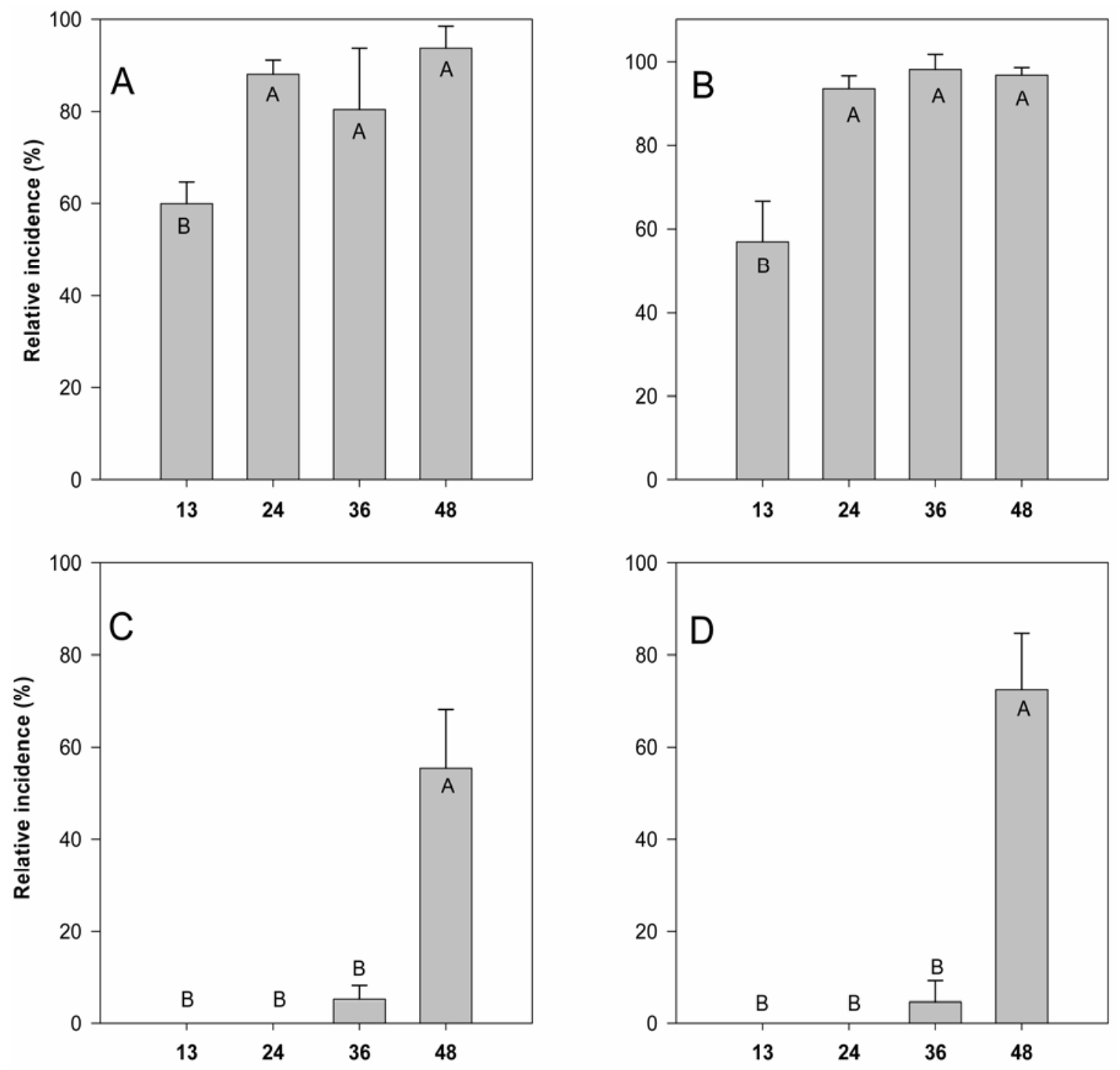

Timing after inoculation (h)

Fig. 2. Effect of time of application of fungicides applied 13, 24, 36, or $48 \mathrm{~h}$ after inoculation on the incidence leather rot of strawberry. Fungicides were A, azoxystrobin; B, pyraclostrobin; $\mathbf{C}$, mefenoxam; and $\mathbf{D}$, phosphite. Disease incidence for each time of application is reported as the percentage relative to the untreated control. Times of application within each fungicide treatment not significantly different at $P=0.05$ are indicated with the same letter. 
inoculation, but was ineffective against citrus melanose when applied at the same timing (3). Similar results in post-infection applications have been observed in other pathosystems $(1,10,23,33)$.

Experiments conducted under controlled conditions with pyraclostrobin indicate that this fungicide has good post-infection activity against anthracnose fruit rot of strawberry when applied within 3 to $8 \mathrm{~h}$ after a wetting event. And, under field conditions, pyraclostrobin provided good post-infection activity of anthracnose fruit rot for up to $24 \mathrm{~h}$ after the occurrence of an infection event (36). Likewise, experiments with $C$. beticola have shown that pyraclostrobin was effective for up to $24 \mathrm{~h}$ after inoculation (17).

Higher levels of disease control may have been obtained in this study with postinoculation times shorter than $13 \mathrm{~h}$. However, for practical purposes, we do not consider it realistic to expect growers to be able to make applications less than $13 \mathrm{~h}$ after the initiation of an infection period under most field conditions. Fungicides that cannot provide a high level of disease control when applied at a minimum of $13 \mathrm{~h}$ after infection do not have sufficient curative activity for use in post-infection fungicide programs. Thus, their use in conjunction with a disease forecasting system for leather rot is greatly limited.

Mefenoxam contains the R-enantiomer of metalaxyl, which possesses strong inhibitory activity against oomycetes and greater efficacy than metalaxyl at lower rates of application $(9,21,35)$. Metalaxyl and mefenoxam move in plant tissues through xylem following the transpiration stream (32). The locally systemic properties of this fungicide aids in providing strong post-infection activity against oomycetes. In addition, translaminar movement of metalxyl has been reported against downy mildew of grape when applied to foliage (39). In our studies, fungicide applications were applied to provide coverage of the entire plant, including the fruit. Although no attempts were made to characterize the movement of mefenoxam from leaves to fruit or through fruit epidermal cells, based on the reported physical mode of action of metalaxyl, it is probable that the fungicide moves into fruit when applied directly to them. Post-infection applications of metalaxyl against Plasmopara viticola on grape leaves have provided $100 \%$ control up to $24 \mathrm{~h}$ after inoculation, and substantial disease reduction for up to 5 days after inoculation (39). In the same crop, it has been found that metalaxyl applied to the leaves and shoots is able to translocate to grape berries, giving excellent disease control even if the fungicide is applied up to $48 \mathrm{~h}$ after inoculation (18).

Phosphite fungicides have been widely used in several crops to control diseases caused by Phytophthora spp. and downy mildews $(2,4,15,16,24,30,37)$. Pre-infection or protectant activity of phosphite fungicides has been used against many different diseases caused by oomycetes with very good results $(2,4,30,34,37)$. Post-infection activity of phosphite fungicides also has been reported. Wicks et al. (38) reported that post-infection applications of phosphorous acid against downy mildew of grape provided a significant reduction of disease incidence and severity for up to 10 days after inoculation. However, Gisi (9) reported that post-infection applications of fosetyl-Al (essentially the same active ingredient as phosphorous acid) against the same pathogen only provided control for up to 2 days. Our results on post-infection control of leather rot with phosphorous acid are similar to previous reports.

Phosphite fungicides are the only known ambimobil fungicides capable of moving upward and downward in plants (5). The high solubility of phosphite fungicides and their systemicity in both the symplast and apoplast (9) greatly favors their efficacy in pre- and post-infection applications. The specific mode of action of these fungicides, particularly their metabolite $\mathrm{H}_{3} \mathrm{PO}_{3}$ (phosphite), still is not clear, but different investigations with various species of Phytophthora $(11,22,25,26)$ support the hypothesis that phosphite interferes with phosphorus metabolism, inhibiting key enzymes affecting different biochemical processes that are essential for Phytophthora spp. growth and development. In addition, some investigations suggest that phosphite fungicides also stimulate the plant defense mechanism (15).

Although no information related to movement of phosphite fungicides into strawberry fruit is available, it is probable that these fungicides move directly into the fruit by diffusion through the epidermis if they are sprayed directly onto them. Phosphite fungicides applied to leaves probably are absorbed and move into the symplast, where they follow the pathway of sources to sink given their high solubility (9). Maturing strawberry fruit would serve as sinks on the strawberry plant; therefore, fungicides applied to leaves probably are absorbed and transported to the fruit, where they accumulate, apparently in sufficient concentration to prevent infection by $P$. cactorum.

In summary, all fungicides tested provided excellent protectant activity against leather rot for up to 7 days, but the QoI fungicides azoxystrobin and pyraclostrobin had weak post-infection activity The ability of mefenoxam and phosphorous acid to provide effective control within a 36-h response period suggests that these fungicides may have potential for use in postinfection fungicide programs where timing is based on the occurrence of predicted infection periods (29). This approach to disease management conforms to current
IPM strategies and could result in improved fungicide timing, improved disease control, reduced overall use of fungicides (especially in drier growing seasons), and increased profits for growers. Further studies will be conducted using a diseasepredictive model for leather rot to evaluate the post-infection activity of mefenoxam and phosphite in the field. The curative activity of these fungicides also could be of benefit to growers even in the absence of disease-predictive systems. For example, if a grower encounters heavy rainfall, especially when flooding events occur, the application of these materials within $36 \mathrm{~h}$ of the initiation of the rain event could aid in preventing a leather rot epidemic.

\section{ACKNOWLEDGMENTS}

This research was supported in part by grants from the North American Strawberry Growers Association, The Ohio Fruit Growers Society, The Ohio Agriculture Research and Development Center, The Ohio State University, and The Nationa Council of Science and Technology (CONACYT), Mexico.

\section{LITERATURE CITED}

1. Anesiadis, T., Karaoglanidis, G. S., and Tzavella-Klonary, K. 2003. Protective, curative and erradicant activity of the strobilurin fungicide azoxystrobin against Cercospora beticola and Erysiphe betae. J. Phytopathol. 151:647-651.

2. Browne, G. T., and Viveros, M. A. 2004. Effects of phosphonate and mefenoxam treatments on development o perennial cankers caused by two Phytophthora spp. on almond. Plant Dis. 89:241-249.

3. Bushong, P. M., and Timmer, L. W. 2005. Evaluation of post infection control of citrus scab and melanose with benomyl, fenbuconazole, and azoxystrobin. Plant Dis. 84:12461249

4. Chaluvaraju, G., Basavaraju, P., Shetty, N. P., Deepak, S. A., Amruthesh, K.N., and Shetty, H. S. 2004. Effect of some phosphorous-based compounds on control of pearl millet downy mildew disease. Crop Prot. 23:595-600.

5. Cohen, Y., and Coffey, M. D. 1986. Systemic fungicides and the control of oomycetes. Annu. Rev. Phytopathol. 24:311-338.

6. Ellis, M. A., and Grove, G. G.1983. Leather rot in Ohio strawberries. Plant Dis. 67:559.

7. Ellis, M. A., Wilcox, W. F., and Madden, L. V. 1998. Efficacy of metalaxyl, fosetylaluminum, and straw mulch for control of strawberry leather rot caused by Phytophthora cactorum. Plant Dis. 82:329-332.

8. Erwin, D. C., and Ribeiro, O. K. 1996. Phy tophthora Diseases Worldwide. American Phytopathological Society Press, St. Paul, MN.

9. Gisi, U. 2002. Chemical control of downy mildews. Pages 199-159 in: Advances in Downy Mildew Research. P. T. N. SpencerPhillips, U. Gisi., and A. Lebeda, eds. Kluwer Academic Publishers, Dordrecht, The Netherlands.

10. Godoy, C. V., and Canteri, M. G. 2004. Efeitos protetor, curativo e erradicante de fungicidas no controle da ferrugem da soja causada por Phakopsora pachyrhizi, em casa de vegetacao. Fitopatol. Bras. 29:97-101.

11. Griffin, J. M., Smillie, R. H., and Grant, B. R. 1990. Alterations in nucleotide and pyrophosphate levels in Phytophthora palmivora following exposure to the antifungal agent potassium phosphonate (phosphite). J. Gen. Microbiol. 136:1285-1291.

12. Grove, G. G., Madden, L. V., and Ellis, M. A. 1985. Influence of temperature and wetness 
duration on sporulation of Phytophthora cactorum on strawberry fruit. Phytopathology 75:700-703.

13. Grove, G. G., Madden, L. V., Ellis, M. A., and Schmitthenner, A. F. 1985. Influence of temperature and wetness duration on infection of immature strawberry fruit by Phytophthora cactorum. Phytopathology 75:165-169.

14. Hoffman, L. E., and Wilcox, W. F. 2003. Factors influencing the efficacy of myclobutanil and azoxystrobin for control of grape black rot. Plant Dis. 87:273-281.

15. Jackson, T. J., Burgess, T., Colquhoun, I., and Hardy, G. E. StJ. 2000. Action of the fungicide phosphite on the Eucaliptus marginata inoculated with Phytophthora cinnamomi. Plant Pathol. 49:147-154.

16. Johnson, D, A., Inglis, D. A., and Miller, J. S. 2004. Control of potato tuber rots caused by oomycetes with foliar applications of phosphorous acid. Plant Dis. 88:1153-1159.

17. Karadimos, D. A., Karaoglanidis, G. S., and Tzavella-Klonary, K. 2005. Biological activity and physical mode of action of the Qo inhibitor fungicides trifloxystrobin and pyraclostrobin against Cercospora beticola. Crop Prot. 24:23-29.

18. Kennelly, M. M., Seem, R. C., Goudury, D. M., and Wilcox, F. W. Translocation of metalaxyl to grapevine fruits from shoot and leaf tissue controls downy mildew (Plasmopara viticola). NY State Agric Exp. Stn. Cornell University. Online publication.

19. Madden, L. V., Ellis, M. A., Grove, G. G., Reynolds, K. M., and Wilson, L. L. 1991. Epidemiology and control of leather rot of strawberries. Plant Dis. 75:439-445.

20. Madden, L. V., Turecheck, W. W., and Nita, M. 2002. Evaluation of generalized linear mixed models for analyzing disease incidence data obtained in designed experiments. Plant Dis. 86:316-325.

21. Marucchini, C., and Zadra. C. 2002. Stereoselective degradation of metalaxyl and
metalaxyl-M in soil and sunflower plants. Chirality 14:32-38

22. McDonald, A. E., Grant, B. R., and Plaxton, W. C. 2001. Phosphite (phosphorous acid): Its relevance in the environment and agriculture and influence on plant phosphate starvation response. J. Plant Nutr. 24:1505-1519.

23. Mueller, D. S., Jeffers, S. N., and Buck, J. W. 2004. Effect of timing of fungicide applications on development of rust on daylily geranium, and sunflower. Plant Dis. 88:657-661.

24. Nelson, M. E., Eastwell, K. C., Grove, G. G., Barbour, J. D., Ocamb, M., and Alldredge, J. R. 2004. Sensitivity of Pseudoperonospora humuli (the causal agent of hop downy mildew) from Oregon, Idaho, and Washington to Fosetyl-Al (Alliette). Plant Health Progress doi: 10.1094/PHP-2004-0811-01-RS.

25. Niere, J. O., DeAngelis, G., and Grant, B. R. 1994. The effect of phosphonate on the acidsoluble components in the genus Phytophthora. Microbiology 14:1661-1670.

26. Niere, J. O., Griffith, J. M., and Grant, B. R. 1990. ${ }^{31} \mathrm{P}$ NMR studies on the effect of phosphite on Phytophthora palmivora. J. Gen. Microbiol. 136:147-156.

27. Piepho, H. P. 1999. Analysing disease incidence data from designed experiments by generalized linear mixed models. Plant Pathol. 48:668-674.

28. Rebollar-Alviter, A., Madden, L. V, and Ellis, M. A. 2005. Efficacy of azoxystrobin, pyraclostrobin, potassium phosphite, and mefenoxam for control of strawberry leather rot caused by Phytophthora cactorum. Plant Heath Progress doi:10.1094/PHP-2005-0107-01-RS.

29. Reynolds, K. M. Ellis, M. A., and Madden, L. V. 1987. Progress in development of a strawberry leather rot forecasting system. Adv. Strawberry Prod. 6:18-22.

30. Rohrabach, K. G., and Schenck, S. 1985. Control of pineapple heart rot, caused by Phytophthora parasitica and P. cinnamomi, with metalaxyl, fosetyl $\mathrm{Al}$, and phosphorous acid.
Plant Dis. 69:320-323.

31. Ross, D. H. 1924. Leather rot of strawberries. J. Agric. Res. 28:357-376.

32. Schwin, F., and Staub, T. 1996. Phenylamides and other fungicides against oomycetes. Pages 323-346 in: Modern Selective Fungicides H. Lyr, ed. Gustav Fischer Verlag, New York.

33. Soto-Estrada, A., Förster, H., Hasey, J., and Adaskaveg, J. E. 2003. New fungicides and application strategies based on inoculum and precipitation for managing stone fruit rust on peach in California. Plant Dis. 87:1094-1101.

34. Stiles, C. M., and Datnoff, L. E. 2005. Evaluation of fungicides for control of Pythium blight in overseeded turfgrasses using a simple field inoculation technique. Plant Health Progress doi:10.1094/PHP-2005-0330-01-RS.

35. Taylor, R. J., Salas, B., and Gudmested, N. C. 2004. Differences in etiology affect mefenoxam efficacy and the control of pink rot and leak tuber diseases of potato. Plant Dis. $88: 301-307$

36. Turecheck, W. W., Peres, N. A., and Werner, N. A. 2006. Pre- and post infection activity of pyraclostrobin for control of anthracnose fruit rot of strawberry caused by Colletotrichum acutatum. Plant Dis. 90:862-868.

37. Vawdrey, L. L., Grice, K. E., Peterson, R. A. and De Favert, J. 2004. The use of metalaxyl and potassium phosphonate, mounds, and organic and plastic mulches, for the management of Phytophthora root rot of papaya in far northern Queensland. Australas. Plant Pathol. 33:103-107.

38. Wick, T. J., Magarey, P. A., Wachtel, M. F., and Frensham, A. B. 1991. Effect of postinfection applications of phosphorous (phosphonic) acid on the incidence and sporulation of Plasmopara viticola on grapevine. Plant Dis. 75:40-43.

39. Wong, P. F., and Wilcox, F. W. 2001. Comparative physical modes of action of azoxystrobin mancozeb, and metalaxyl against Plasmopara viticola (grapevine downy mildew). Plant Dis. 85:649-656. 